\title{
EL LUMBALÚ Y LAS MUJERES TEJEDORAS DE LO ESPIRITUAL Y COMUNITARIO
}

\author{
O LUMBALÚ E AS MULHERES TECELANTES DO \\ ESPIRITUAL E COMUNITÁRIO
}

\author{
THE LUMBALÚ AND THE WEAVING WOMEN OF THE \\ SPIRITUAL AND COMMUNITY
}

\author{
Liliana Parra-Valencia ${ }^{1}$, Emilia Andrea León Chavez ${ }^{1}$, \\ Leidy Giovanna Jaramillo Gutiérrez ${ }^{1}$, Dolores Galindo² e Saulo Luders Fernandes ${ }^{3}$ \\ ${ }^{1}$ Universidad Cooperativa de Colombia, Bogotá, Colombia \\ ${ }^{2}$ Universidade Federal de Mato Grosso, Cuiabá/MT, Brasil \\ ${ }^{3}$ Universidade Federal de Alagoas, Maceió/AL, Brasil
}

\begin{abstract}
RESUMEN: Este artículo, de naturaleza teórica, aborda el Lumbalú, una práctica fúnebre de matriz africana en San Basilio de Palenque (Colombia). Se trata de una forma de grupalidad curadora, como potencial terapéutico con el que cuentan algunas comunidades para contener la experiencia emocional; ámbito de estudio en el que se enmarca el presente artículo. El Lumbalú es expresión de la resistencia afrodiaspórica, que conecta con lo sagrado y donde las mujeres son las hiladoras del tejido espiritual y comunitario. Invitamos a las disciplinas psicológicas y a las Ciencias Sociales y Humanas a la apertura epistemológica y descolonial hacia otras formas comunitarias de comprensión de la muerte, en contextos de guerra, violencia política, neoliberalismo y racismo, en Améfrica.

PALABRAS CLAVE: Ritualidad fúnebre; Matriz africana; Grupalidad Curadora; San Basilio de Palenque.
\end{abstract}

RESUMO: Este artigo, de natureza teórica, é sobre Lumbalú, uma prática funerária da matriz africana em San Basilio de Palenque (Colômbia). É uma forma de grupalidade curadora, como potencial terapêutico que algumas comunidades têm para conter a experiência emocional; campo de estudo em que este artigo está enquadrado. O Lumbalú é expressão da resistência afrodiaspórica, que se conecta com o sagrado e na qual as mulheres são quem fiam o tecido espiritual e comunitário. Convidamos as disciplinas psicológicas e as Ciências Sociais e Humanas à abertura epistemológica e descolonial em direção a outras formas comunitárias de compreensão da morte, em contextos de guerra, violência política, neoliberalismo e racismo, na Améfrica.

PALAVRAS-CHAVE: Ritualidade fúnebre; Matriz africana; Grupalidade curadora, San Basilio de Palenque.

ABSTRACT: This article, of a theoretical nature, is about Lumbalú, a funerary practice of African matrix in San Basilio de Palenque (Colombia). It is a form of Curator grupality, as a therapeutic potential that some communities have to contain emotional experience; scope of study in which this article is framed. The Lumbalu is an expression of afrodiasporic resistance, which connects with the sacred and where women are the spinners of the spiritual and community fabric. We invite the psychological disciplines and the Social and Human Sciences to epistemological and decolonial opening towards other community forms of understanding death, in contexts of war, political violence, neoliberalism and racism, in Amefrica.

KEYWORDS: Funerary ritual; African matrix; Curator grupality, San Basilio de Palenque. 


\section{Introducción}

Desde antiguo, hasta el presente, son las tejedoras y los poetas-astrólogos de las comunidades y pueblos, los que nos revelan esa trama alternativa y subversiva de saberes y de prácticas capaces de restaurar el mundo y devolverlo a su propio cauce. (Rivera-Cusicanqui, 2010, p. 33)

La racionalidad de occidente intenta negar e ignorar la muerte, al dejar por fuera de la construcción de la ciencia, las creencias en torno a ella, concluye Fernando Suazo (2010) en su estudio sobre la muerte, en la cultura maya de Rabinal (Guatemala). La revisión bibliográfica sobre Psicología y muerte, y nuestra propia experiencia formativa en Psicología dan cuenta de un tímido acercamiento al tema, cuando está presente en los debates académicos; caracterizado por centrarse en la intervención de las/los familiares de quien fallece, con una alta referencia a las etapas del duelo, y cuya perspectiva fue introducida por la psiquiatra suizo-americana Elizabeth Kübler Ross (1994), en su texto On death and dying, publicado en 1969.

Sin embargo, otras lecturas no anglosajonas y eurocentradas en torno a la muerte, las encontramos en campos afines a la Psicología, como en el caso de Eduardo Viveiros de Castro (2013), quien aborda, desde la antropología, la noción de muerte bajo la perspectiva amerindia de los pueblos de la Amazonía brasilera. Disciplinas de las ciencias sociales, como la filosofía o la teología se interesan por el estudio de la metafísica, lo infrahumano y trascendente a través de la óptica de los pueblos afrodescendientes e indígenas de Améfrica Ladina (Gonzalez, 1988). Estas comunidades mantienen una cercanía a la muerte, a sus finados, antepasados y ancestros. Es el caso del pensamiento indígena, de acuerdo con la lectura del filósofo brasilero Marco Antonio Valentim (2018) en el libro Extramundanidade e sobrenatureza. Ensaios de ontologia infundamental. En él se acerca a la concepción de mundo de la filosofía occidental moderna y al pensamiento xamánico amerindio. El autor aborda la relación con los no humanos, las dos sabidurías como define a la naturaleza y a la cultura, y la política cósmica.

De acuerdo con Antonio Carlos Diegues (2008), las comunidades tradicionales presentan en su proceso de formación una relación entre el territorio, la naturaleza, las prácticas comunitarias y la vida espiritual. Estos elementos no se presentan escindidos en la vida cotidiana, sino que toman forma, se expresan en el territorio y retroalimentan las formas de pensamientos complejos, al conectar los entes no-humanos, la naturaleza, las experiencias espirituales y la vida humana. Se configura lo que Rita Segato (2018), en Contrapedagogías de la crueldad, conceptualiza como modos de existencia anfibios, que resguardan las prácticas consideradas tradicionales de los ojos colonialistas, pero aparentan reproducir un orden colonial. Allí, opera un juego de resistencia sutil y capaz de producir zonas para la continuidad y el florecimiento de prácticas que escapan a la matriz colonial, de base católica.

Utilizamos la noción Améfrica como categoría político-cultural, siguiendo a Lélia Gonzalez (1988), como un sistema etnogeográfico de referencia que comparten las Américas del sur, centro, norte e insular, que da cuenta de las marcas de la presencia africana en la construcción cultural del continente americano en sus existencias anfibias.

Nuestra formación en la disciplina psicológica tampoco incluyó los debates raciales, ni la literatura producida por autores hombres y mujeres afros o indígenas, de Latinoamérica o el Caribe, África o Asia. Conscientes de este escenario en la formación en Psicología, 
optamos por acercarnos al abordaje de la muerte en una perspectiva afrodiaspórica en la costa Caribe de Colombia; específicamente desde una revisión teórica del ritual fúnebre Lumbalú, de la comunidad de San Basilio de Palenque, con una historia de más de cinco siglos de persecución y resistencia. A pesar del silenciamiento epistémico (ParraValencia, 2019) de los saberes y prácticas afrodiaspóricas, derivado de la esclavización y el genocidio de las poblaciones afrocaribeñas, las religiones, creencias y rituales de matriz africana, se conservan; gracias al arraigo de la relación con la naturaleza, la fuerza espiritual y la ritualidad que sustentan la vida comunitaria, como en el caso de la espiritualidad palenquera.

Los palenques fueron asentamientos empalizados de cimarrones ${ }^{1}$, utilizados como espacio de refugio en el monte, tras su huida de los colonizadores españoles, según Nina de Friedemann (1990), en el territorio que hoy se conoce como Colombia. La conexión con la naturaleza les permitió edificar el palenque con palos, barro, piedras y demás elementos que encontraban en el campo abierto. La vida de las/los cimarrones y palenqueros en condición de huida, se estructuró en la cercanía a la naturaleza, la espiritualidad africana y la vida comunitaria. El palenque hace referencia a un proceso de reorganización y resistencia (Arocha, 2008) de las mujeres y los hombres esclavizados, quienes, en medio de las penurias, el maltrato y la huida, se emanciparon. El palenque es resistencia de las raíces africanas. Durante la colonización española, en los siglos XVI y XVII, según Maria Cristina Navarrete (2011) se llegó a configurar un sistema de palenques en todo el territorio de Montes de María en la Provincia de Cartagena, la costa Caribe colombiana desde Riohacha hasta Panamá, por la ribera del río Grande de La Magdalena, pasando por Mompox, hasta Zaragoza, en la Provincia de Antioquia.

La comunidad de San Basilio de Palenque es heredera de los palenques del siglo XVII. Por Real Cédula emitida por la Corona Española, en 1691, se reconoció la libertad al palenque San Miguel, luego conocido como San Basilio de Palenque (Arrázola, 1970). De allí, su reconocimiento como primer pueblo libre en la América colonial, durante el proceso de esclavitud de los pueblos africanos en la diáspora, antes que la independencia de Haití en 1804 y las demás colonias. En este contexto se conocen defensores de las y los africanos esclavizados en el territorio de Montes de María, resistentes a la colonialidad, como Benkos Biohó en nombre colonial Domingo Biohó, quien nació en Guinea Bissau (oeste de África), conocido como el rey de la Matuna y el rey de Arcabuco (Herreño, 2010). En la actualidad, San Basilio de Palenque es un corregimiento que hace parte del municipio de Mahates, del departamento de Bolívar en Colombia. Se ubica a $50 \mathrm{~km}$ de Cartagena (al interior de la costa Caribe), en las estribaciones de los Montes de María, cercano a María La Baja.

La comunidad de San Basilio de Palenque conserva algunas tradiciones de matriz africana (Mesa et al., 2009), como lo identificamos en la gastronomía, la oralitura y los rituales fúnebres. El espacio cultural de San Basilio de Palenque fue declarado Obra Maestra del Patrimonio Oral e Inmaterial de la Humanidad, en 2005, por la Organización de las Naciones Unidas para la Educación, la Ciencia y la Cultura (Unesco). La comunidad viene experimentando un proceso de reconocimiento de su diversidad cultural, como se observa en la patrimonialización oral e inmaterial. Lo cual puede tener una doble lectura: reconocimiento de una identidad cultural y legado para Colombia y Améfrica o como proceso que conduce a la exotización de prácticas culturales y su creciente subalternización a un orden colonialista. 
Nos interesamos por aquellos saberes para curar que quedaron excluidos por la ciencia moderna y colonial, silenciando el potencial de la comunidad y, en particular, sus prácticas cotidianas. Entendemos la colonialidad como una forma de dominación que reproduce la represión cultural europea de la violenta conquista. Esta impuso una estructura colonial, de los patrones europeos, que instauró discriminaciones raciales y étnicas, en palabras de Aníbal Quijano (1992). El autor plantea que la colonización del imaginario de los/las dominados/as llevó a una relación de dominación colonial entre la cultura europea y las demás, aún después de finalizado el colonialismo político.

Por su parte, Catherine Walsh (2007, p. 58) interesada en el carácter epistémico, político y ético orientado a "la transformación de las matrices del poder colonial", señala la importancia del posicionamiento "otro" del pensamiento y de la praxis que va más allá de lo eurocéntrico. Es decir, aquel que parte de una otredad como alternativa, avizorando una pluriversidad que, en palabras de la autora, abre el diálogo y el posicionamiento crítico con el conocimiento asociado a Occidente y que irrumpe en lo universal. Por descolonialidad entendemos aquella perspectiva que estudia y denuncia la continuidad de las lógicas de dominación coloniales, con la intención de aportar a deconstruir la racionalidad eurocéntrica, no sólo en lo político sino también en lo epistemológico y ontológico. El pensamiento descolonial se basa y se diferencia de las tradiciones teóricas que lo anteceden, como los estudios poscoloniales, el enfoque del sistema-mundo y el paradigma de la dependencia. Desde la perspectiva descolonial se entiende que las relaciones raciales, étnicas, sexuales, epistémicas, económicas y de género quedaron intactas en la descolonización jurídica y política de las colonias, de los siglos XIX y XX (Castro-Gómez \& Grosfoguel, 2007). De manera que, la descolonialidad se encamina hacia el análisis de este tipo de relaciones de dominación, en el siglo XXI. Para el grupo/movimiento modernidad/colonialidad, que surge del Latin American Subalterns Studies Group, desde la Universidad estadounidense, la decolonialidad, como la nombran para diferenciarla de la independencia jurídico-política, complementaría la primera descolonización del siglo XIX, en el caso de las colonias en las Américas.

En la investigación optamos por la noción descolonialidad como una corriente de pensamiento más amplia que incluye diferentes autoras y autores críticos del paradigma moderno y de posturas sin compromiso político de proyectos intelectuales, que reproducen las estructuras coloniales de la dominación y la discriminación (Rivera-Cusicanqui, 2008). La descolonialidad se interesa por pensamientos y posicionamientos otros alternativos al occidental, siguiendo a Walsh (2007), como el que nos invita la práctica ritual del Lumbalú.

Desde la perspectiva descolonial, metodológicamente nos acercamos a las prácticas capaces de subvertir el orden hegemónico colonial en la posibilidad de afirmar y convivir con la diversidad de otros mundos y proyectos de la sociedad que están vivos en Améfrica. Los encuentros con las comunidades campesinas de Montes de María, en el contexto de la investigación Doctoral titulada Grupalidad curadora. Descolonialidad de saberes-prácticas campesinas y afroindígenas, en Montes de María (Caribe-Colombia) (Parra-Valencia, 2019), iniciada en 2015 y finalizada en 2019; nos llevó a interesarnos por los rituales fúnebres del territorio, que aún se conservan en la zona rural. Así, nos acercamos al velorio, el novenario y al Lumbalú, la práctica de velar los muertos de matriz africana Bantú de la espiritualidad de San Basilio de Palenque. La investigación siguió una metodología inspirada en el paradigma cualitativo, interesada en la experiencia subjetiva y afectiva de las propias comunidades, desde un marco interpretativo, de carácter participativo. 
Articulamos diferentes estrategias que incluyeron entrevistas, encuentros centrados en diálogos con sabedoras y sabedores, recorridos por el territorio y el diario de campo. Las entrevistas fueron transcritas y analizadas según lo relacionado con la practica fúnebre del Lumbalú.

El artículo argumenta que el Lumbalú se configura como un proceso de resistencia afrodiaspórica a la colonialidad, que conecta con lo sagrado, donde la mujer es la hiladora del tejido espiritual y comunitario. Se trata de una invitación para ampliar y descolonizar las discusiones de las disciplinas psi y considerar otras posturas no euro-norte centradas sobre lo fúnebre. Más cercanas a las comunidades, en los contextos de guerra, violencia política, neoliberalismo y racismo en Améfrica. El Lumbalú materializa, en la Colombia actual, la relación de las y los habitantes del territorio de San Basilio de Palenque con África, promoviendo una descolonización por medio de las prácticas fúnebres de origen Bantú que los cánones colonialistas judeo-cristianos buscaron capturar bajo la forma de rituales occidentalocéntricos. Y a través de una resistencia al racismo que niega la contemporaneidad del vínculo del pueblo afrocolombiano con África; tanto como la centralidad del papel de las mujeres en las sociedades afrodiaspóricas.

\section{El Lumbalú en San Basilio de Palenque}

El Lumbalú es una de las prácticas de matriz afrodescendiente Bantú, voz lingüística de influencia Ki-Kongo, que nace en la comunidad de San Basilio de Palenque. Se trata de un ritual fúnebre colectivo ( $l u$ y melancólico (mbalú) de la espiritualidad palenquera, que honra a las y los difuntos. La ritualidad de cantos, músicas y bailes del Lumbalú, de los familiares y el Kuagro ${ }^{2}$ al que pertenecía en vida la/el finado, expresa el sentimiento por la pérdida física del ser querido, y conecta con el mundo espiritual para ayudar al alma a pasar del más acá al más allá. En la cultura Bantú, el mundo en que vivimos es un paquete de remedios y esencias que contiene todo lo necesario para la vida. Kimbwandende kia Bunseki Fu-Kiau (1991, citado en Santos, 2019) describe la cosmovisión Bantú como un modo de vivir orientado por la sacralidad del entorno natural que, aunque se puede tocar y sentir, no está separado del mundo inmaterial al cual se accede con la muerte. Además, todos los seres (considerados vivos o inertes por las sociedades occidentales), en la cosmovisión Bantú, están dotados de espíritu, o mejor, dotados de la presencia divina de Kalunga (aquel que está enteramente completo, i.e., lunga):

la Tierra, nuestro planeta, es futu dia n'kisi diakânga Kalûnga un diâmbu diamôyo un sobre (paquete) de esencias/remedios atados por Kalûnga con la intención de la vida en la Tierra. (...) Contiene todo lo que la vida necesita para su supervivencia: esencias/remedios (n’kisi/bilongo), comida (madia), bebida (ndwînu) etc. (Fu-Kiau, 1991, citado en Santos, 2019, p. 11)

El ritual fúnebre del Lumbalú se compone de siete momentos, según Jaime Arocha (2008). El primero es la agonía, en el cual se aproxima el pájaro Kajambá, quien anuncia el deceso. Aquí al individuo agonizante con ayuda de los cantos y bailes del Lumbalú, se le ayuda al buen morir. La muerte es la siguiente fase del ritual (Arocha, 2008), con ella, viene la preparación del cuerpo, la delicadeza de la feminidad viste al finado y lo arregla 
para su presentación en el mundo del más allá (Vergara, Senior, \& Yepes, 2014). En el caso de una persona mayor, es necesario realizar más procesos de limpieza del cuerpo, a fin de que este pueda ser admitido en el mundo del más allá. En cambio, cuando se trata de una niña o un niño, la preparación del cuerpo, su arreglo, es distinto, pues es considerado como alguien puro.

Después de esta preparación se realiza el velorio; se organiza un altar o paño, con la imagen de un Cristo y al respaldo, un vaso con agua, cirios, veladoras, coronas y mariposas de papel que simbolizan que el alma del difunto revolotea por el lugar (Arocha, 2008). Las mujeres cocinan los alimentos preferidos del difunto y se entonan cantos y rezos. Los asistentes estarán en el jardín, descansando, jugando dominó y contando chistes (Arocha, 2008). El ritual fúnebre, además de honrar y agradecer al muerto, expresa que su paso por la tierra trajo alegría a sus allegados y familiares, quienes conservan este sentimiento, aún después de su partida física.

En las últimas fases del Lumbalú se retira el cuerpo del finado de la casa, con ayuda del Kuagro y se pasea por los lugares que frecuentaba, esto es recoger sus pasos. En el recorrido por las calles del palenque, las mujeres que acompañan, simulan recoger maíz y los hombres arroz (Gómez, 2010). En la siguiente etapa, conocida como el entierro, el cuerpo se lleva al cementerio, con la orientación de un guía que porta una cruz. A las 12 de la madrugada, se dan gritos de lekos (canto de dolor).

Después del entierro en el cementerio, se regresa a la casa. En ese momento se reza una novena, pues se considera que los muertos no se van del todo, sino que mantienen contacto con los vivos, y el espíritu sigue siendo parte de San Basilio de Palenque (Arocha, 2008). El penúltimo momento es conocido como última noche; cuando los miembros del Kuagro realizan rondas y juegos, y se sale a pilá el arroz. También se llevan a cabo danzas y cantos para despedir al que ya no está (Arocha, 2008). Se levanta lo que denominan el paño, es decir, el altar, en señal de que el espíritu ya salió de la casa. En el séptimo momento del Lumbalú, cuando se cumple el primer aniversario de muerte, el cabo de año, los familiares y amigos se reúnen y preparan un altar, ubican una prenda del finado y se lleva a cabo otro Lumbalú (Pérez, 2008).

El Lumbalú viene al encuentro de la concepción de persona y su relación con la naturaleza presentes en la cultura Bantú. Esta reúne un conjunto de pueblos que vivía en África central, en las localidades que hoy denominamos Congo, Gabón y Cabinda (provincia de Angola) (Daibert, 2015). La cultura Bantú confiere gran importancia a los antepasados que se tornan en "los guardianes y los protectores de sus parientes vivos" (Daibert, 2015, p. 12). Por tanto, les corresponde a estos últimos mantener su memoria y presencia por medio de rituales salvaguardados, sobre todo, por los ancianos y ancianas que estarían más próximos a los muertos.

\section{Resistencia afrodiaspórica y fortalecimiento comunitario}

La esclavización es un proceso que busca subyugar a las personas con el fin de satisfacer intereses privados; se fundamenta en la discriminación y el racismo. Durante la colonización de Améfrica, y desde la racionalidad eurocéntrica, se consideró a las africanas, los africanos y sus descendientes, como supuestamente "inferiores", objetos y herramienta 
de trabajo para la productividad económica colonial, cuya vida podía ser tomada de forma violenta. Sin embargo, la sagacidad de las/los africanos les permitió generar diversas estrategias de resistencia creativa a la colonialidad, para sobrevivir y para la pervivencia cultural.

Una de esas estrategias consistió en acoger el cristianismo en el seno de las prácticas espirituales afrodiaspóricas, lo que les mereció ser llamados, "negros con alma blanca"; como lo menciona Roger Batisde (2005, p. 323). Al integrar y compartir creencias católicas, los pueblos africanos podían acceder a oportunidades laborales diferentes, como las agrícolas o la elaboración de artesanías, para mejorar las condiciones de vida (Batisde, 2005). Esta alternativa, implicaba una lucha interna por parte de cada sujeto, para aceptar y practicar convicciones en las cuales no creía. Una segunda estrategia es el llamado sincretismo, que permitió fusionar elementos de la cultura afrodescendiente y blanca-europea, para dirimir la disputa entre el dominio de uno sobre otro, con el fin de generar una convivencia entre ambas culturas y lograr un estado de integración (González, 2015). Al mismo tiempo que se expresaba la religiosidad católica judeo-cristiana, también estaban presentes las creencias de la espiritualidad africana en la vida comunitaria, como en el caso del Lumbalú.

Las tradiciones y prácticas palenqueras y cimarronas continúan presentes en los territorios de Colombia donde habitan las comunidades afrocolombianas, como formas de resistencia a la colonialidad; como en Montes de María, el Chocó, la zona plana del norte del Cauca, Guapi (Cauca), Tumaco (Nariño), el archipiélago de San Andrés y San José de Uré (norte de Córdoba). Cimentándose en la memoria, las comunidades afrodescendientes, según Arocha (2008), conservaron los rituales fúnebres de matriz africana. En la actualidad se pueden encontrar todavía, siguiendo a De Friedemann (1990), huellas de africanidad en Améfrica. Desde que las africanas y los africanos en su continente de origen fueron capturados y subidos de manera violenta a los barcos del circuito comercial de personas esclavizadas, sus ideas y prácticas resistieron contra los deshumanizantes tratos y la explotación. Un claro ejemplo de esto, es el ritual del Lumbalú en la comunidad de San Basilio del Palenque, expresión de resistencia colonial y práctica de grupalidad curadora (Parra-Valencia, 2019), transmitida de generación en generación. Esta grupalidad es entendida como la capacidad de ciertas comunidades de contener la experiencia emocional que contribuye a los procesos de cura. La ritualidad fúnebre comunitaria se mueve en la dimensión emancipatoria que fortalece el profundo sentido de comunidad, siguiendo a Maritza Montero (2004), al reafirmar la pertenencia a una lucha compartida con otras y otros para mantener su identidad, tradiciones y creencias espirituales comunes.

La tradición del ritual Lumbalú es entendida desde Améfrica como expresión de los procesos de resistencia afrodiaspórica a la dominación colonial. Aquí coincidimos con Silvia Rivera-Cusicanqui (2010, p. 54) cuando afirma que "la autodeterminación política y religiosa significa una retoma de la historicidad propia, una descolonización de los imaginarios y de las formas de representación”. En el caso del Lumbalú como práctica situada en la Améfrica colonizada, advertimos una alternativa descolonial que resiste a la racionalidad/espiritualidad eurocéntrica. El Lumbalú se configura en una forma de resistencia afrodiaspórica a la colonialidad y de fortalecimiento comunitario, que encarna la práctica de la grupalidad curadora, desde la relación con las fuerzas ancestrales, como capacidad de restitución y manutención de la energía vital, la tierra, la comunidad y del universo de vivos y muertos. 


\section{La espiritualidad palenquera}

En la espiritualidad palenquera está presente la idea del más allá, y la relación con las y los antepasados que enmarcan sus prácticas, donde la relación entre la vida y la muerte es estrecha. "Los muertos son santos y los santos muertos", no son personas que dejaron de existir, sino más bien santos vivos, según Arocha (2008, p .17). Las y los "mensajeros" o intermediarios se comunican con el mundo de las sombras, como denominan los palenqueros a las almas, a los espíritus que habitan el más allá. La espiritualidad afrocolombiana reconoce que la muerte es un proceso donde se deja el cuerpo, mientras que el espíritu retorna hacia aquellas tierras africanas de donde fueron arrancadas millones de personas.

La noción de tiempo para algunas etnias de la cultura africana presenta una temporalidad no causal, ni centrada en la proyección del futuro, como lo concibe la cultura moderna occidental, desde una linealidad entre pasado, presente, y futuro. En las culturas africanas la temporalidad se relaciona con un presente que se vincula a su vez con un pasado, en una comprensión bidimensional, y en la cual el pasado aparece como nodal para comprender las vivencias del presente. El presente está vivo en la relación que se establece siempre con un pasado. Y el futuro también debe ser vislumbrado en el vínculo con las experiencias del pasado.

La concepción del tiempo como un flujo entre pasados y presentes, está potencializado con la práctica de la oralidad en las comunidades negras, que es la base para contar, narrar los acontecimientos vividos y actualizarlos en el presente. El acontecimiento de la muerte sigue la práctica de narrar las vidas y está aliada a la comprensión de la temporalidad como relación entre los pasados y el tiempo presente. El acto de narrar, como afirma Amadou Hampatê Bâ (1983, p. 172), es una tradición viva que tiene en la palabra la capacidad de movilizar las fuerzas y las acciones en el mundo: "Si el habla es fuerza, es porque ella crea un vínculo de vaivén (yaa-warta, en fulfulde ${ }^{3}$ ) que genera movimiento y ritmo, es, por tanto, vida y acción. Este movimiento de vaivén es simbolizado por los pies del tejedor que sube y baja”. Narrar la vida de los antepasados es tener los hilos de la ancestralidad en el presente, al reactivar sus energías y fortalecer el tejido comunitario. Así como también, las vidas personales y colectivas de quienes pasaron al mundo invisible, pero que en el mundo material todavía se hacen presentes.

De tal forma que cuando la persona fallecida es recordada por algunas generaciones, vive una inmortalidad personal, familiar y social, en la cual su grupo de convivencia, sus seres queridos y amigos, recuerdan su vida y la actualizan en el presente. Cuando estas experiencias no son recordadas, se da la muerte individual del sujeto, sin embargo, sus vivencias y prácticas todavía se mantienen vivas con la ancestralidad, en la emergencia de una inmortalidad colectiva presente en su grupo.

Por su parte, los rituales han sido una parte clave en el ámbito social para la compresión de la muerte; se trata de una construcción social que busca acercarse a otros registros de la realidad. En este escenario, la ritualidad está presente en la espiritualidad afrocolombiana. Es importante mencionar que los rituales practicados con otros, como en el Lumbalú de la comunidad de San Basilio de Palenque, permiten que las personas elaboren su duelo colectivamente, al afrontar la tristeza y liberar sus emociones.

Los rituales son considerados una herramienta para la expresión emocional y el desarrollo del apoyo de otras y otros (Yoffe, 2014). Esto incrementa la cohesión y movilización social para acompañar el dolor y propicia estados de serenidad. 


\section{Las mujeres hilan la espiritualidad y lo comunitario}

Para entender los roles de las mujeres de San Basilio de Palenque en los rituales fúnebres y en las prácticas espirituales, es necesario indicar de qué lugar partimos para comprender las relaciones de género. De acuerdo con María Lugones (2008), debemos producir un giro que cambie el análisis de las relaciones de género de un feminismo hegemónico, que tiene como patrón de análisis las experiencias de las mujeres blancas, hacia un análisis que afirma las vivencias de las mujeres negras e indígenas. Con el fin de que sus vidas no sigan sujetas a la mirada restringida de la experiencia de la blanquitud. Al invisibilizar las experiencias de la mujeres negras e indígenas, producimos una separación entre marcadores sociales de género, raza, clase y sexualidad que están alineados con la objetivación de la colonialidad.

Es así, por ejemplo, que las prácticas de maternidad, entre las mujeres negras de territorios marcados por la esclavización en la afrodiáspora, asumen un papel muy diferente al atribuido a las mujeres blancas. Para las mujeres negras, cuyos hijos les fueron arrancados en los procesos de esclavización, la posibilidad de verlos crecer y participar de su formación, es una conquista. Para las mujeres blancas, la maternidad tomó un cariz obligatorio, del cual era necesario apartarse para su emancipación.

En San Basilio de Palenque, el Lumbalú es una práctica intergeneracional, que pasa de madre a hija, por medio de linajes familiares y conecta la maternidad negra a la maternidad ancestral, que es África. Ifi Amadiume (1987) es categórica en demostrar que el patriarcado, como lo conocemos en Occidente, fue introducido en África como parte del proceso de colonización y esclavización, al redefinir la maternidad y el lugar de la mujer como cuidadora. Lo cual no significaba sumisión en las sociedades africanas tradicionales, y cuando existía algún rasgo patriarcal, este convivía simultáneamente con otras lógicas matriarcales, sin ser central.

Las relaciones implícitas entre género y raza son imprescindibles para el análisis de los modos como la colonialidad difunde su proyecto moderno en tierras coloniales. La relación entre el patriarcado y el racismo son líneas que trazan las formas de la colonialidad en la organización de la vida social. Por lo tanto, género y raza no son elementos periféricos en la formación de la colonialidad; por el contrario, las relaciones de género y raza expresan las lógicas de dominación coloniales, enraizadas en el progreso del proyecto moderno/ colonial (Lugones, 2008).

Al estudiar las sociedades yorubas tradicionales, Oyèrónké Oyěwùmí (2004) observa que están presentes marcadores generacionales, según el criterio de antigüedad, en vez de relaciones de género, basadas en criterios de la familia nuclear como en las sociedades occidentales. Al llevar las observaciones de la autora al contex to de las prácticas fúnebres comunitarias de San Basilio de Palenque, no nos corresponde sobreponer a las mujeres en las prácticas comunitarias, una lógica basada en los feminismos blancos y en la historia de las mujeres blancas.

Comprender las categorías de género y raza de forma interseccional, como propone Lugones (2008), nos ayuda en un análisis descolonial. Sin embargo, a pesar de las importantes contribuciones de Lugones al estudio de la colonialidad de género, esta autora no contempla las inflexiones traídas por las autoras negras que ponen en tela de juicio la centralidad de la categoría de género, cuando se trata de las sociedades africanas y afrodiaspóricas (Amadiume, 1987, 1997; Oyěwùmí, 2004). 
En San Basilio de Palenque son las mujeres las que hilan la espiritualidad y los lazos de la comunidad. Su tejido hila mundos visibles e invisibles, dimensiones personales, familiares, colectivas y espirituales. Sobre la mujer afrodescendiente pesa el estigma de fuerza física y robustez. De acuerdo con Eugénio Alves da Silva (2011), en las sociedades tradicionales Bantú, la mujer tiene a cargo el cuidado de la casa, el marido y los hijos y el de la comunidad. Y el matrimonio es un ritual de paso que define y le confiere importancia en la comunidad.

Para las religiones de matriz africana la mujer también es central en los rituales fúnebres celebrados; en cuanto mantiene la vinculación entre los vivos y los muertos. Es ella quien se encarga del cuerpo del difunto, prepara los alimentos y es médium o intermediaria entre el mundo de los vivos y el más allá. Los cantos y bailes de la rezandera ayudan al alma a pasar al más allá, para que el alma no vague (Gómez, 2010).

Las acciones ejercidas por las mujeres en el ritual de Lumbalú expresan la relación compleja entre las dimensiones espirituales, comunitarias, con el territorio, y la naturaleza. Es una comprensión práctica de la vida que no busca escindir la experiencia, sino que la vive en el campo de la multiplicidad que la compone. A pesar de las lógicas coloniales, que operaran en el terreno de las oposiciones y jerarquías entre fenómenos, vivencias y conocimientos e intentan fracturar lo que prioriza la relación sobre lo dual (Lugones, 2014), las mujeres en el Lumbalú tejen lo espiritual. Lo reflejan en lo comunitario, en lo colectivo, en la naturaleza presente en los territorios de los palenques. En la cosmología del Lumbalú, al cantar en el ritual fúnebre, las mujeres guían a los espíritus, separados del continente de origen por la esclavización, de regreso a África. Así, lo narra una de las cantaoras del ritual de Lumbalú en San Basilio de Palenque:

Uno dice que le canta para que no quede su espíritu vagando...para que se vaya para el más allá. Para el más allá es porque nosotros dependemos de África y cuando uno le canta a ese espíritu, se va a descansar en África... El más allá. (Mujer-cantaora, 50 años, San Basilio de Palenque)

No se trata de un ritual fúnebre que sólo trabaja un cuerpo muerto, allí, es reanimado un cuerpo vivo, vinculado a otros cuerpos y a la tierra en la que trabajó, donde vivió y produjo. Fu-Kiau (1991, citado en Santos, 2019), desde la cultura Bantú, nos hace pensar que la humanidad está constituida por más muertos que vivos. Argumenta, además, que en la mediación entre el mundo de las/los ancestros y el de la experiencia vivida, los ancianos y ancianas a cargo de los remedios, enseñan a las/los niños, desde temprana edad, a cantar y a discernir las hierbas. La música es para los bailes y para lo sagrado, es hilo conductor de las prácticas cotidianas de cura.

El Lumbalú, como ritual de origen Bantú, canta a la muerte, a aquel o aquella que muere y al dolor de la comunidad que se despide. Narra la cantaora de Lumbalú, que en el ritual también son cantadas las canciones que a la difunta o al difunto le gustaba oír:

Esa música la cantamos cuando está el hombre tendido en la sala de su casa... Cuando está difunto... En ese momento comienza el ritual del Lumbalú. También a las nueve de la noche. Es el momento en que uno se va a... hacer lo mismo que hacía la persona, lo que le gustaba que le cantara. E igualmente uno canta como esa persona, habla como esta persona...Es ese dolor colectivo que sale del interior de esa persona. (Mujer-cantaora, 50 años, San Basilio de Palenque) 
Como lo muestra Tiganá Santos (2005), basado en los estudios de Fu-Kiau, desde una perspectiva Bantú, la comunidad son los muertos y los vivos - Kânda i (mbûndani a) bafwa ye. Por lo tanto, referirse al papel de la mujer, en las sociedades Bantú, requiere considerar su lugar en esta comunidad ampliada. El orden capitalista y colonial busca delegar las prácticas que son guiadas por cosmovisiones no occidentales del mundo, a una formulación pre-moderna; llamadas por Lugones (2014) no modernas, como una forma de rechazar esta linealidad epistémica e histórica de la narrativa moderna, sobre otros pueblos y proyectos de sociedad. Producciones no modernas, como el Lumbalú, por construir cosmovisiones que relacionan elementos sin una jerarquización entre ellos, se presentan como una forma de enfrentamiento y resistencia a las lógicas coloniales. De ahí, los intentos de negación de estas prácticas en la vida social y las tentativas de cristianización que aparece en los sincretismos.

En la comunidad de San Basilio de Palenque la mujer es considerada la mano derecha de la muerte y es aún más resaltada en el Lumbalú, donde sobresale. Las mujeres se encargan de orientar el ritual, y sin importar la edad, cantan para avisar a las otras almas que alguien nuevo llegará a su mundo, al son de los tambores, según lo menciona Gloria Gómez (2010, citado en Mesa, Piedrahita, Cruz et al.). En el caso del Lumbalú, la mujer también hace posible la expresión del dolor colectivo de la comunidad.

Incluso frente a una lógica patriarcal colonial que fractura y se impone a las vidas colonizadas, existen puntos de creación, subversión e insurgencia dentro de esta racionalidad impuesta (Lugones, 2014). Es desde las márgenes del sistema patriarcal/ colonial que operan los rituales, como el Lumbalú, el cual posibilita el fortalecimiento comunitario y la afirmación de la importancia de las mujeres en la vida en comunidad.

Una reflexión necesaria para analizar la circulación de las lógicas patriarcales en la cotidianidad de las comunidades, es considerar lo que Julieta Paredes (2010) debate sobre la lógica patriarcal moderna/colonial que busca acentuar las asimetrías de género. Así como también las relaciones patriarcales ya existentes en el territorio latinoamericano y en sus comunidades, lo que ella denomina, de entronque patriarcal. Relaciones de poder impresas en las relaciones de género, ya presentes en los territorios tradicionales, fueron reorganizadas e intensificadas con el patriarcalismo blanco occidental. De acuerdo con Lugones (2014), es en las fisuras abiertas por la intensificación del patriarcalismo que podemos afirmar la multiplicidad de las formas de confrontación de las mujeres frente a la colonialidad de género.

En un campo de multiplicidades, entre continuidades, fracturas y rupturas, la mujer ocupa una posición importante dentro del seno comunitario en San Basilio de Palenque; al ser las encargadas de iniciar y cerrar el ciclo de la vida. Es decir, en las culturas africanas y afrodiaspóricas la mujer no es un ser débil que busca protección, como lo han hecho creer miles de cuentos. Por el contrario, es más bien ella quien ayuda y socorre a los que la necesiten. La mujer es quien lidia con la gestación de la vida, y también con la función de devolver a la tierra la energía vital que le pertenece (Ribeiro, 1996).

En conclusión, las mujeres son responsables de ayudar a sanar a su comunidad, pues ellas son las tejedoras espirituales y comunitarias que sostienen no sólo la relación entre la vida y la muerte, sino también entre las personas de la comunidad. Son capaces de seguir tejiendo, en momentos de intenso sufrimiento y dolor, pues, según las culturas africanas de raíz Bantú, guardan la sabiduría de las/los vivos y las/los muertos. 
Como afirma Lugones (2014, p. 950): "Lo teórico aquí es inmediatamente práctico. Mi propia vida - las maneras de usar mi tiempo, de ver, de cultivar una profunda tristeza - está animada por una gran ira e impulsada por el amor.”

\section{Consideraciones finales}

Los rituales constituyen el ámbito religioso y social, donde tanto lo mítico y lo estético subyacen como pilares de significación religiosa sincrética, al tiempo que genera inclusión social desde la integridad y la ética; y ayudan a fortalecer la vida comunitaria. Las prácticas fúnebres de matriz africana, como expresión de la grupalidad curadora presente en el vínculo de la comunidad, potencian la fortaleza y el afrontamiento comunitario.

Contemplar la muerte como un proceso de transformación o cambio, suscita una conexión con el más allá y lo divino. La comunicación con el más allá, más que mantener vivos a las y los difuntos, mantiene con vida a la comunidad y sus ancestros. Esta necesidad de comunicación y expresión que mantiene la espiritualidad afrodiaspórica, promueve la catarsis del dolor psíquico. A la par, se fortalecen los vínculos comunitarios y el apoyo mutuo y se permite contener la tristeza y sentir de la otra y el otro.

Concluimos con una invitación para que la Psicología amplíe los debates sobre lo que cura en las comunidades, desde el territorio, en contextos de guerra, represión o violencia política, como el de Améfrica. Hacia el pensamiento y posicionamientos otros en la construcción de conocimiento. Frente al cuidado, las comunidades tienen sus propias maneras de hacer, de la mano de diversos saberes y prácticas comunitarias, no eurocentradas. Movilizan los recursos comunitarios que les permiten la resistencia y la transformación. Una última provocación, se dirige a la producción de una Psicología que se aproxime, recorra y comprenda las cosmovisiones y filosofías africanas, ricas en sus concepciones de mundo, naturaleza, de lo invisible, humano, no-humano y del tiempo. Las cuales posibilitan diversas lecturas de la realidad, capaces de gestar otros modos de vivir y existir.

\section{Notas}

1 Término utilizado en Colombia para las/los africanos y afrodescendientes que lograron escapar de su estado de esclavitud (Navarro, 2011, p. 3).

2 Se trata de una forma propia de organización que las/los mismos africanos instituyeron, durante la época de colonización. Esta organización se encarga de la trasmisión de conocimiento, hábitos, rutinas y destrezas afro, para fortalecer la cultura palenquera. (Navarro, 2011, p. 173) 


\section{Referencias}

Amadiume, Ifi (1987). Male Daughters, Female Husbands: Gender and Sex in an African Society. Zed Books.

Amadiume, Ifi (1997). Re-Inventing Africa: Matriarchy, Religion and Culture. Zed Books.

Arocha, Jaime (2008). Velorios y Santos Vivos. Museo Nacional de Bogotá. Recuperado de https://fondojaimearocha.com

Arrázola, Roberto (1970). Palenque, primer pueblo libre de América. Historia de las sublevaciones de los esclavos de Cartagena. Ediciones Hernández.

Batisde, Roger (2005). Las Américas Negras (Fragmentos). CESLA, 7, 321-338. https://www. redalyc.org/pdf/2433/243320976018.pdf

Castro-Gómez, Santiago \& Grosfoguel, Ramón (2007). El giro decolonial. Reflexiones para una diversidad epistémica más allá del capitalismo global. Siglo del Hombre.

Daibert, Robert (2015). A religião dos Bantos: novas leituras sobre o Calundu no Brasil colonial. Estudos Históricos, 28(55), 7-25.

Diegues, Antonio (2008). O mito moderno da natureza intocada. NUPUAUB-USP.

Friedemann, Nina (1990). Lumbalú: ritos de la muerte en Palenque de San Basilio, Filología y Lingüistica, XVI(2), 51-63.

Gómez, Gloria. (2010). Las palenqueras cargan su historia. En: María Fernanda Márquez; Catalina Samper Martínez (Eds.). Palenque era una fiesta. Crónicas a ritmo de tambor. (p. 3033). Ministerio de Cultura Colombia, Fundación Nuevo Periodismo Iberoamericano.

González, Enrique (2015). Las Religiones afro-brasileñas negras: Cachimbo, Candomblé de Cabocles, Pagelancia, Macumba, Candomblé, Umbanda y Musulmanes negros. Una visión introductoria. https://ciscuve.org/2015/07/las-religiones-afro-brasilenas-negras-cachimbo-candomble-de-cabocles-pagelancia-macumba-candomble-umbanda-y-musulmanes-negros-una-vision-introductoria/

Gonzalez, Lélia. (1988). A categoria político-cultural de amefricanidade. Tempo Brasileiro, 92/93, 69-82.

Hampaté Bá, Amadou (1983). A tradição viva. In Unesco (Org.), História geral da África. Ática.

Herreño, Ángel (2010). Los derechos en la lucha contra la discriminación racial. Gente Nueva.

Kübler-Ross, Elizabeth (1994). Sobre los muertos y los moribundos. Ediciones Grijalbo.

Lugones, María (2014). Rumo a um feminismo descolonial. Estudos Feministas, Florianópolis, 22(3), 1-18.

Lugones, María (2008). Colonialidad y Género. Tabula Rasa. 9, 73-101.

Mesa, Beatriz, Piedrahita, Juan Carlos, Cruz, Santiago, Rodríguez, Ricardo, Gómez, Gloria Cecilia et al. (2010). Palenque era una fiesta. Crónicas a ritmo de tambor. Ministerio de Cultura. Colombia. https://fundaciongabo.org/es/recursos/publicaciones/palenque-una-fiesta-cronicas-ritmo-de-tambor

Montero, Maritza (2004). Introducción a la Psicología Comunitaria. Paidós.

Navarrete, Maria Cristina. (2011). Los cimarrones de la provincia de Cartagena de Indias en el siglo XVII: Relaciones, diferencias y políticas de las autoridades. RITA. Revue Interdisciplinaire Des Travaux Sur. Les Amériques, 5. http://www.revue-rita.com/dossier/los-cimarrones-de-la-provincia-de-cartagena-de-indias-en-el-siglo-xvii-relaciones-diferencias-y-politicas-de-las-autoridades.html 
Navarro, Luis (2011). Una mirada a las instituciones de San Basilio de Palenque (Colombia) a través de los postulados de Douglass C. North y Thorstein Veblen. Revista de Economía Del Caribe, 9, 162-200. http://rcientificas.uninorte.edu.co/index.php/economia/article/view/3887 Oyěwùmí, Oyèrónké (2004) Conceituando o gênero: os fundamentos eurocêntricos dos conceitos feministas e o desafio das epistemologias africanas. Cordesia Gender Studies, 1, 1-8. Paredes, Julieta (2010). Hilando Fino. Desde el feminismo comunitario. Creative commons. Parra-Valencia, Liliana (2019). Grupalidad curadora. Descolonialidad de saberes-prácticas campesinas y afroindigena en Montes de María (Caribe colombiano). [Tesis de doctorado en Ciencias Sociales y Humanas, Pontificia Universidad Javeriana]. Repositorio institucional PUJ. http://hdl.handle.net/10554/45021

Pérez, Juana (2008). The role of the Palenge languaje in the transmission of afro-palenquero cultural heritage. Museum International. 60(3), 71-79. https://www.researchgate.net/publication/230360507 The Role of the Palenge Language in the Transmission of Afro-Palenquero_Cultural_Heritage

Quijano, Aníbal (1992). Colonialidad y modernidad/racionalidad. Perú Indígena 13 (29), 11 20. https://www.lavaca.org/wp-content/uploads/2016/04/quijano.pdf

Ribeiro, Ronilda I. (1996). A alma africana no Brasil. Os iourubás. Editora Oduduwa.

Rivera-Cusicanqui, Silvia (2008). El potencial epistemológico y teórico de la historia oral: de la lógica instrumental a la descolonización de la historia. En Alejandro Rosillo Martínez et al. (Orgs.), Teoria crítica dos direitos humanos no século XXI (pp. 154-176). EDIPUCRS.

Rivera-Cusicanqui, S. (2010). Ch'ixinakax utxiwa Una reflexión sobre prácticas y discursos descolonizadores. Tinta Limón.

Santos, Tiganá (2005) A tradução de sentenças em linguagem proverbial e o diálogo com o pensamento bantu-kongo a partir de Bunseki Fu-Kiau. Cadernos de Tradução, 16, 49-62.

Santos, Tiganá (2019). A cosmologia africana dos Bantu-Kongo por Bunseki Fu-Kiau: tradução negra, reflexões e diálogos a partir do Brasil. Tese de doutorado, Programa de Pósgraduação em Estudos de Tradução, Universidade de São Paulo, São Paulo.

Segato, Rita (2018). Contrapedagogías de la crueldad. Cactus.

Silva, Eugênio A. (2011). Tradição e identidade de gênero em Angola: ser mulher no mundo rural. Revista Angolana de Sociologia RAS, 8, 21-34.

Suazo, Fernando (2010). La cultura maya y la muerte. Daño y duelo en la comunidad Achi' de Rabinal. Ecap.

Urrea, Fernando. (1990). Cultos afrobrasileños y sistemas de cura: el caso del Candomblé en la sociedad brasilera hoy. Boletín Socioeconómico, 21, 50-66. http://bibliotecadigital.univalle. $\underline{\text { edu.co/handle/10893/5515 }}$

Valentim, Marco Antonio (2018). Fascismo, a politica oficial do antropoceno. Revista Instituto Humanitas Unisinos. http://www.ihu.unisinos.br/584155-fascismo-a-politica-oficial-doantropoceno-entrevista-especial-com-marco-antonio-valentim

Vergara, Berena, Senior, Nurys \& Yepes, Shirley (2014). San Basilio de Palenque: 300 años de libertad. Aguaita, 22., 72-99. https://docplayer.es/13899388-San-basilio-de-palenque$\underline{300 \text {-anos-de-libertad.html }}$

Viveiros, Eduardo. (2013). A morte como quase acontecimento. Palestra. Café Filosófico. Instituto CPFL. 28 de jul. Campinas. https://cpflcultura.com.br/

Yoffe, Laura (2014). Rituales funerarios y de duelo colectivos y privados, religiosos o laicos. Revista de Psicología Unife, 22(2), 145-163.

Walsh, Catherine. (2007). Interculturalidad y colonialidad del poder. Un pensamiento y posicionamiento "otro" desde la diferencia colonial. En Santiago Castro-Gómez \& Ramón Grosfoguel (Eds.), El giro decolonial. Reflexiones para una diversidad epistémica más allá del capitalismo global (pp. 47-62). Siglo del Hombre. 


\section{LILIANA PARRA-VALENCIA \\ https://orcid.org/OOOO-0002-9411-4513}

Doctorado en Ciencias Sociales y Humanas (Pontificia Universidad Javeriana-Bogotá). Maestría en Psicología Social y violencia política (Universidad San Carlos de Guatemala), Maestría en Humanidades (Universidad de Barcelona). Docente-investigadora, coordina la Investigación PsicoPaz del Grupo Boulomai, del Programa de Psicología, Universidad Cooperativa de Colombia (Bogotá).

Endereço: Av. 9 \# 172-96, Bogotá/Cundinamarca.

E-mail: lilianaparrav@gmail.com

\section{EMILIA LEÓN CHÁVEZ}

https://orcid.org/O000-0002-8336-3194

Psicóloga, Universidad Cooperativa de Colombia (Bogotá).

Email: emilia.leonchavez@gmail.com

\section{LEIDY JARAMILLO GUTIÉRREZ}

https://orcid.org/OOOO-0001-8567-5215

Psicóloga, Universidad Cooperativa de Colombia (Bogotá).

E-mail: jaramillogutierrez17@gmail.com

\section{DOLORES GALINDO}

\section{https://orcid.org/0000-0003-2071-3967}

Doutora em Psicologia Social (PUCSP). Professora Associada da Universidade Federal de Mato Grosso (UFMT). Atua como professora permanente nos Programas de Pós-Graduação em Psicologia da Universidade Federal de Mato Grosso (UFMT), Programa de Pós-Graduação em Psicologia e Sociedade (UNESP/Assis) e no Programa de Pós-Graduação em Estudos de Cultura Contemporânea (UFMT).

E-mail: dolorescristinagomesgalindo@gmail.com

\section{SAULO LUDERS FERNANDES}

\section{https://orcid.org/0000-0003-2335-0030}

Doutor em Psicologia (USP). Professor Adjunto da Universidade Federal de Alagoas (UFAL). Atua como professor permanente do Programa de PósGraduação em Psicologia da Universidade Federal de Alagoas.

E-mail: saupsico@gmail.com 


\begin{tabular}{|c|c|}
\hline Histórico & $\begin{array}{l}\text { Recibido: 12/02/2020 } \\
\text { Revisado: 03/06/2020 } \\
\text { Aprobado: 14/06/2020 }\end{array}$ \\
\hline Contribución de los autores & $\begin{array}{l}\text { Concepción: LPV; EL; LJ } \\
\text { Recolección de datos: EL; LJ } \\
\text { Análisis de datos: LPV; EL; LJ } \\
\text { Elaboración del manuscrito: LPV; EL; LJ, DG; SLF } \\
\text { Aprobación final del manuscrito: LPV; DG; SLF }\end{array}$ \\
\hline Consentimiento de uso de imagen & No aplicable. \\
\hline Aprobación, ética y consentimiento & $\begin{array}{l}\text { Apreciado y aprobado por el Comité de Ética en } \\
\text { Investigación del Instituto Fernandes Figueira/ } \\
\text { Fiocruz (CAAE } 36529714.2 .0000 .5269)\end{array}$ \\
\hline Financiamiento & $\begin{array}{l}\text { Universidad Cooperativa de Colombia (Bogotá). } \\
\text { Proyecto INV2159 }\end{array}$ \\
\hline
\end{tabular}




\section{Errata}

En el artículo "EL LUMBALÚ Y LAS MUJERES TEJEDORAS DE LO ESPIRITUAL Y COMUNITARIO”, publicado en la revista Psicologia \& Sociedade, volumen 33 (http://doi. org/10.1590/1807-0310/2021v33234013), en la página 16:

Donde se lee:

Elaboración del manuscrito: EL; LJ, DG; SL;

Léase:

Elaboración del manuscrito: LPV; EL; LJ, DG; SLF 